\title{
DIRETRIZES CURRICULARES NACIONAIS N. 02 DE 2019: A POSSÍVEL DISSOLUÇÃO DO CURSO DE PEDAGOGIA
}

National curriculum guidelines n. 02, 2019: possible dissolution of the Pedagogy course

Diretrices curriculares nacionales n.02 de 2019: la posible disolución del curso de pedagogia

Ângela Maria Silveira Portelinha*

Berenice Lurdes Borssoi**

Vanice Schossler Sbardelotto***

https://doi.org/10.38117/2675-181X.formov2021.v3i1n5.92.113.

\section{Resumo}

O objetivo deste artigo é analisar as Diretrizes Curriculares Nacionais para formação inicial de professores - (DCNFP) 2019, explicitando os conflitos e as contradições para à formação em Pedagogia. Destaca a luta do movimento dos educadores pela necessidade de definir uma política nacional de formação e valorização dos profissionais da educação que não dissocie no campo curricular a docência, a gestão e a pesquisa. Problematiza, a partir das DCNFP/2019, o indicativo de fragmentar essas dimensões no processo formativo-educativo dos cursos de Pedagogia. Com base na pesquisa bibliográfica e documental demonstra que as Diretrizes para o Curso de Pedagogia/2006, atravessada por antagonismos e controvérsias epistemológicas, resultou em uma perspectiva unitária de formação, reafirmada nas DCNFP/2015. Em uma conjuntura política, e econômica, com ajustes fiscais para as políticas sociais, acirra-se a ofensiva neoliberal, e é neste contexto que se aprovam as (DCNFP/2019).

Palavras-chave: Curso de Pedagogia; Diretrizes Curriculares; Formação docente. 
Diretrizes curriculares nacionais n.o 02 de 2019:

A possível dissolução do curso de Pedagogia

\begin{abstract}
This paper aimed at analyzing the National Curriculum Guidelines for teachers' initial training - (DCNFP) 2019, and make explicit conflicts and contradictions for their background in Pedagogy. It highlights the struggle of the educators' movement in order to define a national policy for training and valuing education professionals that does not dissociate teaching, management and research in the curricular area. Based on DCNFP/2019, it questions the indicative of fragmenting these dimensions in the formativeeducational process of Pedagogy courses. According to the bibliographic and documentary researches, the study has shown that the Guidelines for the Pedagogy Course / 2006, crossed by epistemological antagonisms and controversies, resulted in a unitary perspective of background, reaffirmed in the DCNFP / 2015. In a political and economic context, with tax adjustments for social policies, the neoliberal offensive is intensifying, and, in this context, (DCNFP / 2019) are approved.
\end{abstract}

Keywords: Pedagogy course; National Curriculum Guidelines; Teachers’ background.

\title{
Resumen
}

El objetivo de este artículo es de analizar las Directrices Curriculares Nacionales para la formación inicial de profesores -(DCNFP) 2019 explicitando los conflictos y las contradicciones para la formación en pedagogía. Destaca la lucha del movimiento de los educadores por la necesidad de definir una política nacional de formación y valorización de los profesionales de la educación que disocie en el campo curricular la docencia, la gestión y la docencia. Problematiza, a partir de las DCNFP/2019, el indicativo de fragmentación esas dimensiones en el proceso formativo-educativo de los cursos de pedagogía. Con bases en la investigación bibliográfica, y documental, demuestra que las Directrices para el Curso de pedagogía/2006 atravesadas por antagonismos y controversias epistemológicas, resulta en una perspectiva unitaria de formación reafirmada en las DCNFP/2015. En una conyuntura política y económica, con ajustes fiscales para las políticas sociales, se intensifica la ofensiva neoliberal y es en este contexto que se aprueban las (DCNFP/2019).

Palabras clave: Curso de Pedagogía; Directrices Curriculares; Formación docente.

\section{Introdução}

O curso de Pedagogia desde a sua criação em 1939, não manteve o mesmo perfil profissional. Houve um período que formava: o técnico em educação e o docente para as escolas normais; o especialista em educação, com ênfase nas habilitações de orientação, 
supervisão, administração e inspeção escolar e no mesmo curso o docente para atuar nas disciplinas pedagógicas nos cursos de magistério de $2^{\circ}$ grau. Somente em 1980, a partir de algumas experiências isoladas de algumas instituições de ensino superior (IES) é que o curso de Pedagogia começa a assumir a formação docente para os anos iniciais do Ensino Fundamental (AIEF) e docentes para atuar na pré-escola.

No contexto de democratização do estado, seguido da forte presença de políticas neoliberais, muitas discussões e debates sobre a educação e a formação de professores foram realizados evidenciando também posições antagônicas relativas aos rumos do curso de Pedagogia, uma vez que apresentava diferentes propostas, o que dificultava imprimir uma identidade ao curso.

Desta forma, em 2006, as Diretrizes Curriculares Nacionais para o Curso de Pedagogia (DCNCP) são homologadas na tentativa de manter certa unidade em âmbito nacional considerando as diferentes realidades das IES formadoras. O tripé docênciagestão-pesquisa foi assegurado junto a necessidade de formar o professor da Educação Infantil (EI) e dos AIEF no nível superior, sem descaracterizar a produção acadêmica voltada aos aspectos do planejamento, gestão de sistemas, avaliação, currículo, didática, que marca a história do curso de Pedagogia.

Em todas as reformulações, ora para técnico, ora especialista, ora docente para os AIEF e EI, ora para docência-gestão e pesquisa, a discussão e a defesa foi assegurar o espaço acadêmico da Pedagogia, enquanto campo teórico-investigativo que estuda o fenômeno educativo na totalidade e historicidade, nas propostas dos cursos. Portanto, os fundamentos da educação e as teorias didático-pedagógicas estiveram presentes, porém, devido ao perfil profissional que cada reforma aponta, há uma ameaça constante. É neste caminho que se problematizam as DCNFP/2019 e os desdobramentos para o curso de Pedagogia.

Desse modo, o objetivo deste estudo é analisar os desdobramentos das Diretrizes Curriculares Nacionais para a formação inicial de professores (DCNFP) de 2019, para a formação docente no curso de Pedagogia e também destacar a luta de um movimento de trabalhadores da educação, intelectuais e pesquisadores do campo de formação de professores no Brasil, especialmente a Associação Nacional dos Profissionais da Educação (ANFOPE). Entidade que esteve sempre na defesa de curso que integre a formação unitária e não fragmentada, uma visão da práxis educacional, escolar e do trabalho docente, em que a docência é a base da formação, relacionada intrinsicamente com pesquisa e gestão. 
Na primeira seção do artigo, apresenta-se o contexto em que as DCNCP de 2006 se desenvolvem. Na segunda, analisa-se o perfil consolidado no curso a partir desta diretriz, que dimensiona a formação fundamentada na articulação entre docência, pesquisa e gestão. Na terceira, identifica-se uma perspectiva de descaracterização e dissolução do curso de Pedagogia proposta pela Resolução CNE/CP n 2/2019 (DCNFP), documento que indica a formação inicial em percursos formativos distintos. Para o desenvolvimento do texto utilizou-se da base referencial crítica, em pesquisa bibliográfica e documental - Resolução CNE/CP n.1/2006 (DCNCP), Resolução CNE/CP n.2/2015 (DCNFP/2015) e n. 2/2019 (DCNFP/2019), além de Boletins da Anfope.

A Anfope tem sido uma associação nacional de luta pela formação dos profissionais da educação e sempre à frente com um movimento que se articula na defesa de uma perspectiva de curso de Pedagogia que supere a lógica fragmentada, que perpassou pela sua construção histórica, com vista à formação sólida teoricamente e metodologicamente, além disso, defende a autonomia das Universidades na elaboração de seus projetos institucionais de formação, uma das condições essenciais para a elevação da qualidade do ensino, sem ser confundida com o mero ranqueamento por desempenho de instituições educacionais, professores e estudantes.

Sendo assim, a relevância de se aprofundar a análise das DCNFP/2019 que inferem na formação do curso de Pedagogia, recentemente aprovadas, identificando suas proposições e contradições. Como bem aborda Marx, "a reflexão sobre as formas da vida humana e também sua análise científica, percorre um caminho contrário ao do desenvolvimento real. Ela começa post festum e, por conseguinte, com os resultados prontos do processo de desenvolvimento" (MARX, 2017, p. 150). Portanto, a compreensão das políticas de formação de professores se faz no processo, mas também importa uma análise científica que vai para além do real, desvelando assim consensos, ideias hegemônicas, contradições, ideologias, bem como resistências.

\section{O Contexto das DCNCP/2006 para o curso de Pedagogia: a expressão de um conformismo em torno de um consenso}

A conjuntura social, econômica e política da década de 1990 no Brasil marcou a política educacional de formação de professores. Primeiro, pela implementação de um projeto social de racionalidade neoliberal, aliado às demandas do capital internacional, intensificado no Governo Fernando Henrique Cardoso (1995-2002) e segundo, pela 
introdução de inúmeras reformas, decorrentes desse projeto, que atingiram diversos setores da sociedade, sobretudo, a educação básica e superior, o papel das universidades na formação inicial e continuada de professores.

No conjunto de reformas educacionais estava a discussão de concepções de educação e formação, concepções pedagógicas que inferem até hoje na formação de professores. Tais concepções emergem das relações históricas e sociais, ou seja, é fruto do embate de projetos de sociedade, que se opõem. De um lado, uma concepção de sociedade que defende a educação e a formação docente pela ótica produtivista e de mercado, perspectiva a-histórica e pragmática. Por outro lado, uma concepção que considera a educação e a formação de professores sólida teoricamente, como práxis que possibilita refletir sobre o fenômeno da educação e seus determinantes, bem como o docente reconhecer-se como sujeito histórico e social.

Entre debates e embates de propostas formativas antagônicas, se hegemonizam, (pela correlação de forças), as propostas pró-neoliberalismo, com uma formação voltada à prática, a empregabilidade, mas que também atende demandas históricas de luta, como a formação em nível superior de professores dos anos iniciais do Ensino Fundamental e Educação Infantil, por exemplo.

A organização do trabalho se modifica, de fragmentada passa a exigir um trabalho mais integrado. Nesse sentido, a escola pública se torna alvo de interesses tanto dos governos quanto das elites dirigentes, que questionam a formação dos docentes (FREITAS, 1996, 2002). Isto fez com que as políticas de formação de professores, alinhadas às políticas neoliberais, expressassem a necessidade da formação de um novo trabalhador polivalente, flexível e adaptável às incertezas colocadas pelo sistema produtivo. É nessa conjuntura neoliberal que a formação de professores ganhou centralidade na Lei de Diretrizes e Bases da Educação Nacional, (LDBEN) n. 9394/1996, seguida de inúmeras reformas curriculares.

O processo de formulação das diretrizes curriculares nacionais para os cursos de graduação, desencadeado em 1997, pelo Ministério da Educação (MEC) e Conselho Nacional de Educação (CNE), estava relacionado à necessidade de "ajuste" das universidades às novas exigências dos organismos internacionais, em particular do Banco Mundial e do Fundo Monetário Internacional (FREITAS, 1999), visando à adequação da formação de profissionais em nível superior, a fim de atender às demandas do mercado globalizado. Naquele momento o curso de Pedagogia não entrou no processo de debate. 
Desta forma, ganha destaque a discussão do CNE acerca das Diretrizes Curriculares Nacionais para os cursos de graduação e a formação docente, em nível superior, (DCNFP) aprovadas em 2002, Resolução CNE/CP 1, de 18 de fevereiro de 2002 e Resolução CNE/CP 2, de 19 de fevereiro de 2002. A reforma curricular dos cursos de graduação tornou-os mais flexível e menos especializada, com a eliminação da figura dos "currículos mínimos". Contudo, cabe questionar para quem tornou-se mais flexível e menos especializada? Para todas as licenciaturas? Ou somente para o curso de Pedagogia?

No campo da formação de professores, os cursos de licenciatura das áreas específicas do conhecimento foram questionados por apresentarem por um longo período, uma organização por campo do conhecimento, exemplo dos cursos de Ciências Sociais, que habilitavam em um mesmo curso professores para o ensino da Geografia, História e Sociologia como também os cursos de Ciências Naturais voltado ao ensino da Biologia, Matemática, Física e Química. Na contramão, o curso de Pedagogia organizava-se em habilitações com foco para ser especialista em uma das funções da organização do trabalho pedagógico e gestão escolar.

Considerando o movimento histórico do curso de Pedagogia, o mesmo inverte-se, tornando-se mais flexível para a Pedagogia, visto que o curso possui um vasto campo de atuação profissional e mais especializado para as demais licenciaturas, no que se refere aos objetos do ensino.

Havia uma orientação de reorganização dos currículos dos cursos de graduação pautada em princípios de: “a) flexibilidade na organização curricular; b) dinamicidade do currículo; c) adequação às demandas do mercado de trabalho; d) integração entre graduação e pós-graduação; e) ênfase na formação geral; f) definição e desenvolvimento de competências e habilidades gerais [...]" (CATANI; OLIVEIRA; DOURADO; 2001, p. 74).

Em 2003, CNE instituiu uma Comissão Bicameral, formada por conselheiros da Câmara de Educação Superior e da Câmara de Educação Básica, para tratar das Diretrizes Curriculares Nacionais para o Curso de Pedagogia. O objetivo dessa comissão era acolher diversas propostas - do CNE, de associações acadêmico-científicas, comissões e grupos de estudos e pesquisa sobre a educação básica e a formação de profissionais da educação; sindicatos e entidades estudantis participantes diretos na implementação da política nacional de formação desses profissionais e de valorização do magistério; e propostas de estudantes e professores do curso de Pedagogia. Na audiência pública, em dezembro do 
mesmo ano, ficou evidente a diversidade de posições em termos de princípios, formas de organização do curso e de titulação a ser oferecida pelo Curso de Pedagogia.

O CNE, considerava o pedagogo um licenciado com atuação tanto na docência quanto nas funções requeridas conforme o artigo 64 da LDBEN n. 9394/1996. Com formação para a docência, ele não seria apenas professor, por isso o uso do termo pelo CNE de "docente/educador", com espaço de atuação em instituições escolares e nãoescolares, bem como a produção e difusão do conhecimento científico e tecnológico.

Para o CNE, a Pedagogia é uma "ciência" e um "campo de formação" de educadores - docentes e não docentes. É uma ciência que produz um saber acadêmico, passível de dar sustentação à prática docente e ao trabalho pedagógico, escolar e não escolar; é um campo teóricoinvestigativo sobre a educação e o ensino. Explicita-se aqui sua dupla configuração: a Pedagogia é campo de estudos e campo de formação profissional - do docente e do gestor. (EVANGELISTA; TRICHES, 2017, p. 175).

Para a Anfope e entidades apoiadoras, o pedagogo é um profissional que atua na educação escolar e não-escolar, é uma formação abrangente e com uma nova compreensão de docência - base formativa do licenciado em Pedagogia. Um profissional concebido como aquele que trabalha diretamente com a formação humana, produção de conhecimentos e organização do trabalho pedagógico escolar e não-escolar e na educação básica. A docência é base e identidade, bem como a produção de conhecimento articulados à gestão.

A elaboração das diretrizes da Pedagogia expressa contradições, ambiguidades e rupturas, intensificando a polarização entre professor versus especialista, generalista e especialista, professor versus pedagogo, como também conhecimento específico e conhecimento pedagógico, Universidade e Institutos superiores de educação.

Havia um debate polêmico em relação ao curso, que vinha perpassando desde sua constituição histórica. Os projetos em disputas eram: a) da Anfope e entidades apoiadoras, representados pelos pesquisadores Leda Scheibe, Helena de Freitas, Iria Brzezinski, Márcia Aguiar e Merion Bordas; b) dos signatários que assinaram o Manifesto dos Educadores, representados por Carlos Libâneo, Selma Garrido Pimenta e Maria Amélia Franco; c) do $\mathrm{CNE}^{1}$. A proposta menos aceita e que não se convalidou foi a do Manifesto, o qual tinha como propositiva o bacharelado para formar o Pedagogo e a licenciatura para

\footnotetext{
${ }^{1}$ Sobre esse debate polêmico, ver Evangelista e Triches (2008), Libâneo (2006) e Borssoi (2012).
} 
Diretrizes curriculares nacionais n.o 02 de 2019:

A possível dissolução do curso de Pedagogia

formar o professor. Esses projetos se assentavam em três concepções, que se confrontavam:

a pedagogia centrada na docência, enquanto licenciatura; a pedagogia centrada na ciência da educação, como espaço de formação dos especialistas, enquanto bacharelado; e a pedagogia que integrava as duas dimensões, formando o professor e o Pedagogo unitário em um mesmo percurso, uma vez que a defesa da formação de especialistas na graduação foi se fragilizando ao longo do tempo, embora a LDBEN, intempestivamente, as resgatasse, com o que se ampliaram as divergências e as dificuldades. (RODRIGUES; KUENZER, 2007, p. 45).

As disputas centraram-se nos diferentes interesses de proposta para essa formação docente. Os debates realizados pelos fóruns entre a Comissão Bicameral e representantes da área buscaram a negociação de alguns elementos desse processo de reforma do curso, destacando-se: "a instituição do entendimento da Pedagogia como Ciência, o que traz como decorrência a necessidade do debate em torno do estatuto epistemológico da Pedagogia" e "a ampliação dos campos de atuação profissional que ultrapassa a docência dos anos iniciais e educação infantil" (SOARES, 2010, p. 40).

No que diz respeito à base de formação no curso de Pedagogia, o desacordo se assentou em relação à docência, tornando-se o núcleo de sustentação formativa do curso. Em relação à discussão sobre o perfil profissional, as ambiguidades foram quanto:

a) à formação restrita ao exercício da docência; b) docência integrada à $\mathrm{OTP}^{2} /$ gestão e pesquisa que ao tomar a docência como base coloca a gestão e a pesquisa em segundo plano; c) docência, OTP/gestão e pesquisa indissociáveis e d) docência como atividade profissional do professor e gestão e pesquisa como atividades profissionais do Pedagogo (SOARES, 2010, p. 47).

Após um longo período de debates e tensões entorno da formação no curso de pedagogia, em 2006 foram aprovadas as diretrizes curriculares para o Curso, pela Resolução CNE/CP n. 1/2006. Embora marcada por antagonismos e controvérsias epistemológicas, resultando em consensos frágeis, mas necessários para encaminhamentos futuros, a elaboração das DCNCP de 2006 (ao suscitar intensos debates) promoveu um campo fecundo de reflexão, análise e proposições para à formação dos profissionais da educação.

\footnotetext{
${ }^{2}$ Organização do trabalho pedagógico.
} 
Por ser o último curso de licenciatura a homologar suas Diretrizes Curriculares, após as DCNFP de 2002, elaborou e ampliou princípios sustentadores para o processo formativo-educativo: assume a concepção de docência como ato educativo metódico e intencional com base nos conceitos, princípios e objetivos da Pedagogia; investe na concepção de educação crítica e emancipatória aliando à concepção de formação humana histórica e social; defende a formação do professor da Educação Infantil e anos inicias do Ensino fundamental na Educação Superior; sustenta a pesquisa como princípio formativo e a produção do conhecimento; assume a unidade da relação entre teoria e prática e no campo profissional a indissociabilidade entre docência-pesquisa e gestão.

Sendo assim, o curso de Pedagogia torna-se um espaço de "a) estudos sistemáticos e avançados na educação, lócus de pesquisa e produção de conhecimento; b) formação do docente e c) formação do gestor, cuja soma resulta no educador" (EVANGELISTA; TRICHES, 2017, p. 176).

Por considerar a rica tradição e contribuição do curso de Pedagogia na formação dos profissionais da educação rejeita os princípios de competência e habilidades das DCNFP de 2002. No entanto, abre possibilidade de muitas áreas de atuação pelo mesmo profissional, ocasionando dificuldades para as IES formadoras adequarem os componentes curriculares aos campos de atuação requeridos, e, ao mesmo tempo, não fragilizar o aprofundamento teórico-metodológico no processo de ensino-aprendizagem.

\section{Perfil consolidado dos egressos do curso, a partir do desenho curricular da Resolução. CNE/CP n. 02/2006: docência - pesquisa e gestão}

A Resolução CNE/CP n ${ }^{\circ} 1 / 2006$, que institui as Diretrizes Curriculares Nacionais para o curso de Graduação em Pedagogia, licenciatura (DCNCP) refere-se ao curso como:

[...] formação inicial para o exercício da docência na Educação Infantil e nos anos iniciais do Ensino Fundamental, nos cursos de Ensino Médio, na modalidade Normal, e em cursos de Educação Profissional na área de serviços e apoio escolar, bem como em outras áreas nas quais sejam previstos conhecimentos pedagógicos (BRASIL, 2006, Art. $2^{\circ}$ ).

Uma formação ampla, que possibilite ao egresso atuar em vários espaços, dá o tom para o novo curso de Pedagogia. Institui-se dessa forma a denominação "Licenciado em Pedagogia" para designar a abrangência da área profissional. "[...] o reconhecimento do título tende a ser transferido da habilitação - porque representa uma especificidade - 
para a área profissional, como expressão de um potencial polivalência (RAMOS, 2002, p. 410)".

As críticas relativas à abrangência profissional e ao inchaço curricular não ficaram ausentes do processo de elaboração e regulamentação das DCNCP/2006. O alerta era para uma possível polivalência, caracterizando a atividade docente como trabalho intensificado e precarizado, podendo, ainda, incorrer no perigo de legitimar, a longo prazo, as condições objetivas para satisfazer um nicho do mercado em expansão. A sustentação poderia vir da necessidade da formação continuada em cursos de Pósgraduação, especialmente os de nível lato-sensu, ofertados em sua maioria pela iniciativa privada, para atender as especificidades de um curso generalista.

As DCNCP/2006 indicam que este curso deve ser o local privilegiado para a formação dos professores da Educação Infantil e anos iniciais do Ensino Fundamental. O que impacta drasticamente o curso. As instituições privadas, em geral, transformaram seus cursos Normais Superiores em cursos de Pedagogia e nas instituições públicas, houve a necessidade de reorganizar os projetos de curso, destinando mais espaço, na carga horária para a área de formação específica.

O curso diminuiu o tempo para as discussões mais abrangentes sobre o processo educativo, de fundamentos da educação e ampliou o espaço para as áreas teórico-práticas, bem como, para a prática como componente curricular e estágios supervisionados. Ainda assim, não foi possível equacionar adequadamente a organização do curso, pois as discussões, sobretudo da área de fundamentos da educação, ficaram limitadas pelo tempo curricular. Algumas disciplinas tiveram as cargas horárias reduzidas em decorrência da necessária inserção de outros componentes curriculares que atendessem ao disposto na diretriz.

Para Saviani (2012), as diretrizes em questão provocaram uma pulverização de assuntos no curso de Pedagogia, de forma que passou a ter como características, a difusão, a fragilidade e superficialidade da formação para a regência nos anos iniciais. Para o autor, as diretrizes são "ao mesmo tempo, extremamente restritas e demasiadamente extensivas: muito restritas no essencial e excessivas no acessório" (SAVIANI, 2012, p. $58)$.

No entanto, há uma retomada dos conceitos de docência, gestão e produção de conhecimento, que estavam presentes no documento da Anfope (2006), e afirmavam que na formação e trabalho docente estes campos deveriam estar articulados e não justapostos. 
E isso exigiria das IES o desafio de elaborar projetos formativos com foco para essa articulação.

Quanto a estrutura do curso, a DCNCP/2006 estabeleceu uma organização por núcleos: um núcleo de estudos básicos; outro de aprofundamento e diversificação de estudos e ainda, um núcleo de estudos integradores.

O consenso em torno do curso dos anos 2000 resolveu, por um lado, a problemática da formação em nível superior dos professores da EI e AIEF. Porém, por outro, criou dificuldades prático-organizacionais nos cursos. A dificuldade de aprofundar aspectos dos fundamentos da educação e as especificidades didáticas e metodológicas de cada segmento redundou em fragilidades formativas dos egressos. Isso se percebe, mesmo com a tentativa de articular, em cada segmento, a docência, a gestão e a pesquisa, como processo indissociável na organização do trabalho pedagógico, principalmente nos estágios supervisionados. ${ }^{3}$

Até meados da década de 2010, disciplinavam a formação de professores para a Educação Básica, as resoluções aprovadas em 2002 sendo específicas de cada curso de licenciatura e finalmente, a resolução que instituiu a Diretriz para o curso de Pedagogia. Porém, ao longo desta década um período de efervescência das disputas políticas no país, o CNE produz a Resolução CNE/CP n. 02/2015, que ao revogar, na verdade, atualiza as resoluções n. 01 e n. 02 de 2002, incorporando os princípios basilares da Base Comum Curricular, construída historicamente pelo movimento dos educadores.

As DCNFP/2015 expressam em seu conjunto a necessidade de promover a articulação entre formação inicial e continuada, IES e sistema de Ensino. Ancoradas nos princípios na DCFCP/2006 estende o desafio de articular a docência, a gestão e a pesquisa para todos os profissionais da educação. Essas diretrizes foram elaboradas num cenário social, econômico e político adverso, decorrente da crise econômica mundial. No Brasil aparece em 2013 com várias manifestações de rua e espaços públicos, os jovens pediam o não aumento da tarifa de ônibus e passe livre para estudantes urbanos (GOHN, 2017).

No ano seguinte, em 2016, a ebulição da crise política, que culminou com o impeachment da presidenta Dilma Rousseff, ocasionou mudanças das equipes que formulavam e coordenavam as políticas de formação no Ministério da Educação e no

\footnotetext{
${ }^{3}$ Ver pesquisa de Portelinha e Ghedini (2021) que, a partir do Estágio Supervisionado e Seminários Integradores, relatam uma experiencia sobre a possibilidade de articular a docência, a gestão e a pesquisa em um curso de Pedagogia de uma universidade pública do Paraná.
} 
Conselho Nacional de Educação. Com isso, também se altera a perspectiva política da condução da elaboração, de tentativas de construção coletivas, para um formato mais centralizador e conservador.

Michel Temer, ao assumir a Presidência da República e alinhado a um Congresso Nacional conservador, encaminhou inúmeras reformas, entre elas: a Emenda Constitucional n. 95, que institui um Novo Regime Fiscal (NRF) no país, congelando os gastos públicos por 20 anos - a medida inviabiliza as políticas públicas sociais, como na educação básica e superior; a Reforma Trabalhista; a Reforma do Ensino Médio e da Base Nacional Comum Curricular (BNCC) - 2017.

Estas medidas estão alinhadas aos interesses do capital internacional, tanto em educação como trabalho, uma política econômica de favorecimento do "mercado", com princípios do neoliberalismo. Este se tornou, nos últimos anos, uma doutrina econômica ou ideologia, uma racionalidade de mundo, que estrutura e organiza tanto as ações dos governantes como a própria conduta dos governados. Não é simplesmente a continuidade do liberalismo clássico do século XVIII, nem a sua negação, mas um "sistema normativo que ampliou sua influência ao mundo inteiro, estendendo a lógica do capital a todas as relações sociais e a todas as esferas da vida" (DARDOT; LAVAL, 2016, p. 7).

A política educacional e de formação de professores não são imunes a essa conjuntura. A legislação emanada desse período de intensas disputas no contexto nacional, seja pela hegemonia de projetos políticos ou de debates teóricos sobre possibilidades de enfretamento do déficit de formação de professores, direcionou a formação para os anos iniciais em cursos teórico-práticos, com ênfase na prática pedagógica em sala de aula e foco nas metodologias de ensino das áreas específicas. Foi assim que os cursos de Pedagogia, por exemplo, responderam às diretrizes de $2006 \mathrm{e}$ 2015.

\section{A dissolução do curso de Pedagogia proposta pela Resolução CNE/CP n. 02/2019: da articulação à fragmentação dos percursos formativos}

Em 2019, sem muito debate coletivo, o CNE promulga uma nova Diretriz de formação de professores, revogando a Diretriz de 2015. E desta vez, a nova proposição alcança todos os cursos de formação de professores, inclusive o curso de Pedagogia. A nova diretriz, coloca no cenário uma nova proposição: cursos específicos para a formação de professores para a Educação Infantil, para os anos iniciais, para os anos finais do Ensino Fundamental e Ensino Médio. Indica que os cursos de formação de professores 
devem ter 3.200 horas, divididos em três grupos distintos de carga horária. É no segundo grupo que a diretriz indica que devem existir três tipos de cursos:

Art. 13. Para o Grupo II, que compreende o aprofundamento de estudos
na etapa e/ou no componente curricular ou área de conhecimento, a
carga horária de 1.600 horas deve efetivar-se do $2^{\circ}$ ao $4^{\circ}$ ano, segundo
os três tipos de cursos, respectivamente destinados à: I - formação de
professores multidisciplinares da Educação Infantil; II - formação de
professores multidisciplinares dos anos iniciais do Ensino
Fundamental; e III - formação de professores dos anos finais do Ensino
Fundamental e do Ensino Médio (BRASIL, 2019, p. 7)

A Diretriz não aponta ou reconhece a experiência acumulada sobre o processo de formação para os anos iniciais e Educação Infantil no curso de Pedagogia, ou parte de análise detalhada dos problemas existentes nas diretrizes anteriores para que em sintonia com as pesquisas sobre formação de professores indique sua superação. Tal feito poderia demonstrar o amadurecimento do debate sobre o enfretamento da difusão, superficialidade e fragilidade, que eram encontrados no curso, o que não ocorre, além de trazer à cena uma nova problemática: a criação de um novo curso. De forma oposta às pesquisas, a Diretriz indica que o curso de Pedagogia retroaja aos idos dos anos de 1960, época que foi marcada pela instituição das habilitações.

Art. 22. A formação para atuar em Administração, Planejamento, Inspeção, Supervisão e Orientação Educacional para a Educação Básica, nos termos do art. 64 da LDB, ou com centralidade em ambientes de aprendizagens e de coordenação e assessoramento pedagógico, pode-se dar em: I - cursos de graduação em Pedagogia com aprofundamento de estudos nas áreas de que trata o caput e que possuam uma carga horária mínima de 3.600 (três mil e seiscentas) horas; [...]. (BRASIL, 2019, p. 11 - grifo nosso)

Os cursos de mestrado e doutorado são indicados para especialização da atuação em área específica, não se destinando a aperfeiçoamento dos processos de ensino e aprendizagem, como requisitos para formação docente. Evidencia-se, nesta diretriz, que o foco da formação é o ambiente da sala de aula, o domínio técnico de conceitos curriculares e métodos de ensino. Conserva desse modo a dicotomia entre teoria e prática, da práxis, pela qual, o processo de ensino escolar é orientado para a formação de um tipo de ser humano e sociedade. Ou seja, busca traduzir na diretriz de formação, uma perspectiva neutra, asséptica e técnica de ensino, como se estes fossem atributos do processo educacional. 
Vale ressaltar, a título de reflexão, a partir da pesquisa de Sbardelotto (2020) a experiência de formação de professores em Portugal ${ }^{4}$, por entendermos a proximidade entre as duas propostas. Embora distinta, especialmente no que se refere ao curso de mestrado, a experiência de formação de professores para os anos iniciais em Portugal, ocorre de maneira similar à proposta pela nova diretriz - com curso específico para tal. O postulante ao magistério dos anos iniciais precisa cumprir o curso de Licenciatura em Educação Básica (LEB), de três anos e adicionalmente, um ramo, dos cinco possíveis, de mestrado, com duração de dois anos.

A formação em LEB privilegia os conteúdos curriculares do ensino básico, enquanto o mestrado, de caráter obrigatório, se dedica a formação pedagógica. A formação está voltada para o exercício do ensino em sala de aula. De acordo com a divisão das cargas horárias dos cursos, prevista no Decreto-Lei n. ${ }^{\circ}$ 79/2014, as questões de formação na área educacional geral, não ocupam $10 \%$ da carga horária em nenhuma das fases de formação e,

[...] embora a formação de professores corresponda agora ao nível de mestrado, não se pode concluir que o tempo dedicado à formação pedagógicodidática e de contato com as situações profissionais tenha aumentado. Por outro lado, foram introduzidas diretrizes que voltaram a contribuir para a divisão entre educadores de infância e professores de diferentes níveis de ensino. (MOURAZ; LEITE; FERNANDES, 2012, p. 06).

Com o foco voltado à prática da sala de aula, com assento nos conteúdos curriculares de ensino básica, a experiência portuguesa parece antecipar os resultados pretendidos pela Resolução CNE/CP n. 02/2019. Com cursos cada vez mais distantes de debates abrangentes e da unidade entre teoria e prática na formação de professores.

Nesse sentido, a perspectiva formativa que subjaz a proposição da Diretriz de 2019, de ênfase na prática restrita da sala de aula, empobrece a formação de professores, que perde em possibilitar autonomia intelectual aos professores, tornando-os cada vez mais dependentes de receitas e métodos elaborados fora da dinâmica entre ensino e pesquisa, na formação.

\footnotetext{
${ }^{4}$. A formação dos professores para o primeiro ciclo em Portugal foi analisada na pesquisa de doutorado de Vanice Schossler Sbardelotto, durante o estágio doutoral na Universidade de Lisboa, Portugal. A pesquisa, que investigou a formação dos professores para o ensino de Geografia nos anos iniciais, constatou que a formação naquele país ocorre em dois ciclos, de licenciatura e mestrado, com foco nos conteúdos de ensino e na prática da sala de aula. (SBARDELOTTO, 2020)
} 
Criar percursos diferenciados para a formação de professores da EI e AIEF, praticamente desconsiderando os longos anos de experiência acumulada em práticas e pesquisas no curso de Pedagogia sobre a necessidade de articular no processo formativo docência e gestão, descolada de uma necessária valorização do magistério, não parece apontar para a superação da fragilidade, superficialidade e difusão de campos de atuação que o curso protagoniza.

A perspectiva de formação das diretrizes da Resolução CNE/CP n. 2/2019 parece se vincular a preparação de um profissional baseado na figura do 'notório saber', instituído pela Lei n. 13.415/2017, que modifica o inciso IV do artigo 61 da LDB.

IV - profissionais com notório saber reconhecido pelos respectivos sistemas de ensino, para ministrar conteúdos de áreas afins à sua formação ou experiência profissional, atestados por titulação específica ou prática de ensino em unidades educacionais da rede pública ou privada ou das corporações privadas em que tenham atuado, exclusivamente para atender ao inciso V do caput do art. 36 (BRASIL, 1996).

Esse tipo profissional descaracteriza à docência e sua relação com pesquisa e gestão, colocando em questão a desprofissionalização e precarização do trabalho dos professores. De acordo com a posição da Anfope no Boletim n. 4 (ANFOPE, 2019) "o Parecer $22^{5}$ abre espaço para a desprofissionalização do magistério e a precarização e alienação do trabalho do professor e para a desqualificação da formação de crianças, jovens e adultos ameaçando o direito à educação", descaracteriza a formação de professores.

A Anfope $(2019,2020)$ defendeu a implantação da Resolução CNE/CP n. 2/2015, como resistência às concepções impostas à educação e a formação indissociável de uma política de valorização profissional dos professores.

A perspectiva formativa proposta pela Resolução CNE/CP n. 02 de 2019, restrita a sala de aula, com empobrecimento da formação de professores e sua atuação autônoma intelectualmente, está alinhada às mudanças no mundo do trabalho. Indica uma desvalorização profissional com a perda gradativa de direitos sociais e trabalhistas conquistados há anos.

Cumpre constar que esta resolução é acompanhada de um anexo denominado de BNC - formação. Com base nas três dimensões da ação docente "I - conhecimento profissional; II - prática profissional; e III - engajamento profissional.” (BRASIL, 2019,

\footnotetext{
${ }^{5}$ Este Parecer antecede a Resolução CNE/CP n. 2, de 20 DE dezembro de 2019.
} 
Diretrizes curriculares nacionais n.o 02 de 2019:

A possível dissolução do curso de Pedagogia

p. 2). O documento caracteriza-se pela prescrição de um conjunto de competências e habilidades requeridas aos professores e que correspondem às competências gerais e as aprendizagens essenciais estabelecidas na BNCC-Educação Básica (2017).

Uma formação fundamentada em princípios de competência e habilidades remete para a teoria do capital humano ${ }^{6}$, noções de sociedade dos conhecimentos, pedagogia das competências e de empregabilidade (FRIGOTTO; CIAVATTA; RAMOS, 2005). Se torna um mecanismo de controle do mercado e do capital, inferindo significativamente no processo de formação e trabalho, gerando conformismo das políticas de ensino básico e superior. Nessa perspectiva de formação, os professores perdem

a compreensão, de um lado, de que o trabalho é uma relação social e que esta relação, na sociedade capitalista, é uma relação de força, de poder e de violência; e, de outro, de que o trabalho é a relação social fundamental que define o modo de existência, e que, enquanto tal, não se reduz à atividade de produção material para responder à reprodução físico-biológica (mundo da necessidade), mas envolve as dimensões sociais, estéticas, culturais, artísticas, de lazer, etc. (mundo da liberdade) (FRIGOTTO, 2012, p. 21).

A formação de professores para toda a Educação Básica, na Educação Superior, foi um avanço histórico. Sobretudo porque essa formação, de acordo com Goergen (2003) deve ser ampla, garantindo uma formação humana para além as práticas profissionais que serão desempenhadas pelo egresso. Desta forma, enveredar para uma formação nos moldes da Resolução CNE/CP n. 02/2019, que restringe a formação à estrita atividade profissional trará impactos significativos ao processo educativo escolar, para a formação das crianças, pois abdica de um professor intelectual e prefere o tarefeiro.

\section{Conclusão}

O processo de elaboração das DCNCP de 2006 revelou as contradições, embates e disputas tanto na formulação de políticas para a educação, alinhadas a ordem econômica neoliberal, quanto no interior do debate educativo no país, expressando posições distintas.

\footnotetext{
${ }^{6}$ A noção de capital humano foi formulada a partir das pesquisas de Theodor Schultz (1973) sobre a desigualdade de desenvolvimento econômico, anos de 1950. As noções de sociedade do conhecimento e de pedagogia das competências para a empregabilidade, foram elaboradas a partir do final dos anos 1980. Elas instauram um senso comum sobre a visão linear de sociedade, difundido nos documentos dos organismos internacionais, sobretudo, pelo Banco Mundial (BIRD), Organização Mundial do Comércio (OMC), Banco Interamericano de Desenvolvimento (BID), tendo forte apoio de grande imprensa, e são incorporadas pelos governos de países periféricos e semiperiféricos, com a ilusão do desenvolvimento (FRIGOTTO; CIAVATTA; RAMOS, 2005).
} 
Ângela Maria Silveira Portelinha, Berenice Lurdes Borssoi e Vanice Schossler Sbardelotto

O seu resultado expressou um curso com abrangência de componentes curriculares decorrentes dos vários campos de atuação conferidos ao licenciado em Pedagogia.

Se por um lado legitimou o espaço no ensino superior para formação dos professores da EI e AIEF, por outro incorreu no distanciamento dos conhecimentos dos fundamentos da educação e dos didático-pedagógicos, uma vez que na organização curricular abrigou conhecimentos teóricos e práticos das especificidades dessas etapas e outras temáticas discutidas na contemporaneidade. No entanto, segue articulado com a Educação Básica, com a escola pública, produzindo conhecimentos e experiências que enriquecem o processo educativo.

Ao sublinhar essas problemáticas, nos associamos a outros pesquisadores que apontam para a necessária discussão sobre a identidade e formação do pedagogo. Mas não nos aproximamos de posições que atentam para a dissolução da Pedagogia, desconsiderando sua trajetória histórica de produção do conhecimento na gestão e na pesquisa como também na formação de professores de anos iniciais e da educação infantil. A necessidade reside em extrair do movimento da realidade concreta as experiências constituídas que conseguem articular docência, pesquisa e gestão no processo formativo.

Pontuamos em nossa análise que a discussão não se resume a dividir ou não o curso, o ponto nevrálgico da nova diretriz é a transformação desse professor em tarefeiro, não afeito ao debate educacional, incapaz de produzir, gerir e organizar o trabalho pedagógico. O conjunto de competências e habilidades requeridas aos professores são da ordem cognitiva, psicofísica e emocional, expresso na dimensão do engajamento social. Para engajar-se socialmente não seria necessário um conjunto de "competências" políticas a serem aprendidas em qualquer processo formativo?

- Competência para compreender os ajustes econômicos que causam incertezas e desemprego crescente;

- Competência para não desistir da profissão e continuar ensinando mesmo em um cenário em que direitos são usurpados;

- Competência para utilizar de toda a criatividade e arremedos tecnológicos e ainda cobrar do estado as condições necessárias para desenvolver o trabalho;

- Competência para continuar estudando na busca permanente por formação e qualificação quando o pensamento negacionista toma conta da sociedade; 
- Competência para lidar com os improvisos e resistir aos arremedos das políticas governamentais formuladas por amadores pedagógicos;

- Competência para continuar na defesa da escola e IES públicas como instrumento de igualdade e justiça social, na defesa da ciência e da socialização do conhecimento científico, resistindo a tudo que ameaça a retirada da autonomia e da nossa capacidade de teorizar sobre os problemas da realidade.

Por fim, isso conduz a necessidade de continuarmos defendendo uma formação teórica e prática consistente para o curso de Pedagogia, que supere noções de sociedade alienada e se afirme em uma concepção de educação mais ampla, plural e unitária. Sem negar as problemáticas históricas desse curso, manter uma fervorosa defesa do mesmo, para que os profissionais nele formados sejam comprometidos com a formação de sujeitos históricos, políticos, sociais, culturais e cientificamente preparados para agirem democraticamente e garantirem seus direitos de uma vida digna.

\section{Referências}

ANFOPE. Documento Final - XIII Encontro Nacional. Faculdade de Educação UNICAMP. Campinas/SP: Unicamp, 2006.

ANFOPE. Boletim Anfope n.4 - Ano 2019. Descaracterização da Formação de professores: Aprovação do Parecer 22 - a BNC da Formação. Anfope, 2019.

ANFOPE. Boletim Anfope n.5 v.30 - Ano 2020. Mais ataques à Formação vindos do CNE. Anfope, 2020.

BORSSOI, B. L. Tensões e possibilidades do estágio curricular supervisionado como potencializador da formação e da perspectiva política do pedagogo. Dissertação de Mestrado. Porto Alegre: Universidade Federal do Rio Grande do Sul (UFRGS), 2012.

BRASIL. Lei n. 9394 de 20 de dezembro de 1996. Estabelece as diretrizes e bases da educação nacional. Diário Oficial da União, p. 27833, 23 de dezembro de 1996.

BRASIL. CNE. Resolução CNE/CP n. 1, de 18 de fevereiro de 2002. Institui as Diretrizes Curriculares Nacionais para a Formação de Professores da Educação Básica, em nível superior, curso de licenciatura, de graduação plena. Diário Oficial da União, Brasília, 9 de abril de 2002. Seção 1, p. 31.

BRASIL. CNE. Resolução CNE/CP n. 02, de 04 de março de 2002. Institui a duração e a carga horária dos cursos de licenciatura, de graduação plena, de formação de professores 
Ângela Maria Silveira Portelinha, Berenice Lurdes Borssoi e Vanice Schossler Sbardelotto

da Educação Básica em nível superior. Diário Oficial da União, Brasília, 04 março 2002. Seção 1, p. 9.

BRASIL. Ministério da Educação. Resolução CNE/CP n. 1, de 16 de maio de 2006. Diretrizes Curriculares Nacionais para o Curso de Graduação em Pedagogia, licenciatura. Diário Oficial da União, Brasília, 16 de maio de 2006, Seção 1, p. 11.

BRASIL. Ministério da Educação. Base Nacional Comum Curricular. Brasília: MEC, 2017.

BRASIL. CNE. Resolução CNE/CP n. 2, de $1^{\circ}$ de julho de 2015. Define as Diretrizes Curriculares Nacionais para a formação inicial em nível superior (cursos de licenciatura, cursos de formação pedagógica para graduados e cursos de segunda licenciatura) e para a formação continuada. Diário Oficial da União, Brasília, 2 de julho de 2015. Seção 1, n. 124, p. $8-12$.

BRASIL. CNE. Parecer n. 22/2019. Define as Diretrizes Curriculares Nacionais para a Formação Inicial de Professores para a Educação Básica e institui a Base Nacional Comum para a Formação Inicial de Professores para a Educação Básica - a BNC da Formação. Novembro de 2019.

BRASIL. CNE. Resolução CNE/CP n. 2, de 20 de dezembro de 2019. Define as Diretrizes Curriculares Nacionais para a Formação Inicial de Professores para a Educação Básica e institui a Base Nacional Comum para a Formação Inicial de Professores da Educação Básica (BNC-Formação). Diário Oficial da União, Brasília, 15 de abril de 2020. Seção 1, p. 46-49.

BRASIL. Emenda Constitucional n. 95, de 16 de dezembro de 2016. Altera o Ato das Disposições Constitucionais Transitórias, para instituir o Novo Regime Fiscal, e dá outras providências. Diário Oficial da União, Brasília, DF, 2016a. Disponível em: http://www.planalto.gov.br/ccivil_03/constituicao/emendas/emc/emc95.htm. Acesso em: 22 fev. 2021.

CATANI, A. M.; OliveIRA, J. F. de; DOURADO, L. F. Política Educacional, mudanças no mundo do trabalho e reforma curricular dos cursos de graduação no Brasil. Educação \& Sociedade. Campinas/SP, Ano XXII, n 75, agosto 2001.

DARDOT, P. LAVAL, C. A nova razão do mundo: ensaio sobre a sociedade neliberal. Tradução Mariana Echalar. São Paulo: Boitempo, 2016.

EVANGELISTA, O.; TRICHES, J. Diretrizes Curriculares Nacionais para o Curso de Pedagogia: Docência, Gestão e Pesquisa. Anais AnpedSul - VII Seminário de Pesquisa em Educação da Região Sul. Itajaí/SC: UNIVALE, 2008.

EVANGELISTA, O.; TRICHES, J. Docência, gestão e pesquisa nas Diretrizes Curriculares Nacionais para o Curso de Pedagogia. Revista Internacional de Formação de Professores (RIFP), Itapetininga, v. 2, n.4, p. 166-188, 2017. 
Diretrizes curriculares nacionais n.o 02 de 2019:

A possível dissolução do curso de Pedagogia

FREITAS, H. C. L. de. O trabalho como princípio articulador na prática de ensino e nos estágios. Campinas/SP: Papirus, 1996.

FREITAS, H. C. L. de. A reforma do Ensino Superior no campo da formação dos profissionais da educação básica: as políticas educacionais e o movimento dos educadores. Educação \& Sociedade. São Paulo, ano XX, n 68, Dez. 1999.

FREITAS, H. C. L. Formação de Professores no Brasil: 10 anos de embate entre projetos de formação. Educação e Sociedade, Campinas/SP, vol. 23, n. 80, set. 2002.

FRIGOTTO, G. Trabalho, conhecimento, consciência e a educação do trabalhado: impasses teóricos e práticos. In: GOMEZ, C. M. Trabalho e Conhecimento: dilemas na educação do trabalhador. São Paulo: Cortez, 2012.

FRIGOTTO, G., CIAVATTA, M.; RAMOS, M. Educação Profissional e desenvolvimento. In. UNESCO. Internacionl Handbook of Education for Changing World of Work. Bom, Germany, UNIVOC, 2009. p. 1 307-1319. Coletânea organizada pelo Centro Internacional de Educação Técnica e Profissional, com o patrocínio da UNESCO. Berlim, 2005.

GOERGEN, P. Universidade e responsabilidade social. In: LOMBARDI, J. C. Temas de pesquisa em educação. Campinas: Autores Associados, 2003. Cap. 1, Parte III, p. 101122.

GOHN, M. da G. Manifestações e protestos no Brasil: correntes e contracorrentes na atualidade. São Paulo: Cortez, 2017.

LIBÂNEO, J. C. Diretrizes curriculares da pedagogia: imprecisões teóricas e concepção estreita da formação profissional de educadores. Educação e Sociedade. Campinas: CEDES, v.27, n.96, out. 2006.

MARX, Karl. O capital: crítica da economia política: Livro I: o processo de produção do capital. Tradução de Rubens Enderle. São Paulo: Boitempo, 2017.

MOURAZ, A.; LEITE, C.; FERNANDES, P. A Formação Inicial de Professores em Portugal Decorrente do Processo de Bolonha: Uma Análise a Partir do "Olhar" de Professores e de Estudantes. Revista Portuguesa de Pedagogia, Coimbra, n. 46-2, p. 189209, 2012.

PORTELINHA, A. M. S.: GHEDINI, C. M. O estágio supervisionado como espaço formativo da profissionalidade do pedagogo. Revista Hipótese, Itapetininga, v. 7, n. único, p. 262-279, 2021.

PORTUGAL. Decreto-Lei n. ${ }^{\circ}$ 79/2014. Ministério da Educação e Ciência. Aprova o regime jurídico da habilitação profissional para a docência na educação pré-escolar e nos ensinos básico e secundário, Diário da República, Lisboa, 92, 14 maio 2014. 2819 - 2828 
Ângela Maria Silveira Portelinha, Berenice Lurdes Borssoi e Vanice Schossler Sbardelotto

RAMOS, M. A educação profissional pela pedagogia das competências e a superfície dos documentos oficiais. Revista Educação Sociedade. Campinas - SP, v. 23, n. 80, p. 401422 , setembro/2002.

RODRIGUES, M. de F.; KUENZER, A. Z. As Diretrizes Curriculares para o Curso de Pedagogia: uma expressão da epistemologia da prática. Revista Olhar do Professor. Ponta Grossa, p. 35-62, 2007.

SAVIANI, D. A pedagogia no Brasil: história e teoria. 2. ed. Campinas, SP: Autores Associados, 2012.

SBARDELOTTO, Vanice Schossler. O ensino de geografia para os anos iniciais do ensino fundamental na formação do pedagogo. 2020. $259 \mathrm{f}$ Tese (Doutorado em Geografia) - Universidade Estadual do Oeste do Paraná, Francisco Beltrão, 2020.

SOARES, S. T. O processo de construção das Diretrizes Curriculares Nacionais para o curso de pedagogia no Brasil (1996-2006): ambiguidades nas propostas de formação do Pedagogo. Dissertação de Mestrado. Universidade Federal do Paraná - UFPR. Curitiba/PR: UFPR, 2010.

$* * *$

Recebido em: 23 fev. 2021. Aprovado em: 02 mai. 2021.

* Angela Maria Silveira Portelinha é Pós-doutoranda em Educação pela UNICAMP. Doutora em Educação pela Universidade Federal do Rio Grande do Sul (UFRGS). Professora do Curso de Pedagogia e do PPGE da Universidade Estadual do Oeste do Paraná (UNIOESTE), Campus de Francisco Beltrão. Membro do Grupo de Pesquisa "Educação Superior, Formação e Trabalho Docente" (GESFORT).

E-mail: amportelinha@yahoo.com.br

ORCID: https://orcid.org/0000-0002-0432-4809

** Berenice Lurdes Borssoi é Doutoranda em Educação pela UNICAMP. Mestre em Educação pela Universidade Federal do Rio Grande do Sul (UFRGS). Professora do Curso de Pedagogia da Universidade Estadual do Oeste do Paraná (UNIOESTE), Campus de Foz do Iguaçu. Membro do Grupo de Pesquisa "Educação Superior, Formação e Trabalho Docente" (GESFORT) e "Políticas de ação educativa, avaliação, mídias e formação de professores" (PAMFOR).

E-mail: bere_borssoi@hotmail.com

ORCID: https://orcid.org/0000-0001-7002-5738 
Diretrizes curriculares nacionais n.o 02 de 2019:

A possível dissolução do curso de Pedagogia

*** Vanice Schossler Sbardelotto é Doutora em Geografia pela Universidade Estadual do Oeste do Paraná (UNIOESTE). Professora do Curso de Pedagogia da UNIOESTE, Campus de Francisco Beltrão. Membro do Grupo de Pesquisa "Educação Superior, Formação e Trabalho Docente" (GESFORT) e membro do Grupo de Pesquisa "Representações, Espaço, Tempo e Linguagens em Experiências Educativas" (RETLEE).

E-mail: vanice.sbar@gmail.com

ORCID: https://orcid.org/0000-0003-4551-768X 